\title{
La participación del prosumidor en la nueva era de la comunicación
}

\section{The participation of the prosumer in the new era of communication}

\author{
Dennys Jordán Correa \\ Universidad Internacional del Ecuador, Ecuador \\ Cindy Arias Valladolid \\ Universidad Internacional del Ecuador, Ecuador \\ Gabriela Samaniego Rivas \\ Universidad Internacional del Ecuador, Ecuador
}

Autor para correspondencia: dejordaco@uide.edu.ec, ciariasva@uide.edu.ec, gasamaniegori@uide.edu.ec

Fecha de recepción: 10 de Septiembre de 2017- Fecha de aceptación: 15 de Noviembre de 2017

\section{Resumen}

La tecnología promueve que las comunidades sean más interactivas y el prosumidor es el protagonista. Ellos generan información como parte de la nueva ola del conocimiento; en algunos casos, trastocando estereotipos y ejerciendo influencia en la forma de elaborar y consumir contenidos. De allí la necesidad de enfocarse en una educación que sea capaz de entrenar a estos generadores de información para que produzcan textos idóneos. En la sociedad actual, los prosumidores representan la corriente digital más grande desde la revolución industrial; en esta época, el mensaje puede ser individual; y, sobre todo, segmentado.

Palabra claves: prosumidores; productos comunicacionales; multimedia; información

\begin{abstract}
Technology promotes that communities are more interactive and the prosumer is the protagonist. They generate information as part of the new wave of knowledge; in some cases, changing stereotypes and exerting influence in the way of elaborating and consuming contents. Hence the need to focus on an education that is able to train these generators of information to produce suitable texts. In today's society, prosumers represent the largest digital current since the industrial revolution; at this time, the message can be individual; and, above all, segmented.
\end{abstract}

Key words: prosumers; communication products; multimedia; information 


\section{Introducción}

La forma de comunicación pasó de lo físico a lo abstracto. Su punto de inicio fueron símbolos, gestos, gritos, señales, gruñidos y la piedra que usaban los antepasados como medio para tallar figuras. Poco a poco, la facultad innata del ser humano cambió, revolucionando la forma de comunicar: el telégrafo, protagonista de la nueva era de la transmisión codificaba a través de ondas eléctricas; y, por ende, evidenció una evolución de la esencia como humanos.

En aquella época, su principal característica era la inmediatez en la emisión de información y la distancia que ésta alcanzaba; sin embargo, estos fueron desapareciendo gracias al desarrollo tecnológico. Dentro del progreso de los medios de comunicación, la ciencia virtual eliminó a los elementos iniciadores; por ejemplo, el mensajero se reemplazó por los correos digitales donde predomina la velocidad de datos (Islas \& Carmona, 2008).

La ecología de medios, "metadisciplina compleja y sistémica cuyo objeto de estudio son los cambios que han producido las tecnologías y los medios de comunicación en las sociedades" (Islas, 2015) muestra la interacción existente con los medios y a través de ésta resume la forma que influye en la sociedad y las posibilidades de supervivencia. Se trata de un estudio de entes mediáticos y su influencia en la opinión de los demás, la percepción y el entendimiento para aceptar o no una verdad.

Dicha interacción entre el hombre y su contexto en la era digital es la base en la ecología. Aquí, sistema, argumento y reacción son los principales elementos en la interpretación de la masa y afectan a al ser humano. La tecnología influye en esta relación con los medios de comunicación; y, se evidencia en la transformación de la información. Con la llegada de internet, el receptor -además de ser consumidor de medios- está capacitado para difundir y compartir contenido, convirtiéndose en prosumidor.

Este término se lo utilizó, por primera vez, en los años 80 y su función era atraer masas, manteniendo el consumo sin preocuparse de satisfacer necesidades; por ejemplo cuando se crea contenido para internet o se discute en cualquier red social, esta persona se convierte en prosumidor. Esta palabra es la combinación de: productor y consumidor, compilación creada en 1980 por Alvin Toffler, en su libro Tercera ola (García-Galera \& Valdivia, 2014) y va más allá de la creación de contenidos informáticos.

Una de las características de este grupo de personas es que su opinión cuenta; pues al ser proactivos, expresan lo que piensan con el fin de ayudar a los demás. Los prosumidores contrastan opiniones y difunden temas con diferentes perspectivas. Si no lo comprueban no lo creen; así producen y comparten su opinión. Así también, mediante su producto, tratan de difundir el conocimiento para que la gente asuma la importancia de compartir para influir; de esta manera, sus opiniones llegan a muchos de sus seguidores generando aprendizaje y conocimiento.

\section{Desarrollo}

Los consumidores de medios, al dar su juicio en cualquier plataforma digital, se comprometen en ser agentes de ayuda para los demás, siendo participativos; y, lo más 
importante, permanentes en lo que están transmitiendo. A su vez pueden adquirir conocimientos de la red; así, luego producen un producto mejorado y que capte el interés de sus seguidores (Rodriguez, 2015).

En la actualidad hay vasta información; pero, esto no implica la veracidad de todo lo publicado; por eso, se requiere de buscadores certeros y cuya información aporte valor. Hay más de doscientos millones de blogs y de estos un 54\% con material de Twiter esto aumenta los resultados de búsqueda debido a los enlaces generados; no todos son productores de su contenido, hay quienes se limitan solo a opinar sobre publicidad, marcas o productos ya que los consumidores confían más en sus recomendaciones que en la promoción gráfica tradicional.

Hay quienes reciben sugerencias, difunden temas de interés y de forma implacable. En esta época, la innovación es una característica fundamental y se ubica un paso adelante de lo que le interesa a la gente (Kovach \& Rosenstiel, 2012). La comunicación es versátil y también los promusidores. Una misma persona puede mostrar diferentes escenarios porque utiliza la tecnología y todas las herramientas que ésta contiene para construir un anuncio con contenido jocoso (meme) para Facebook o un vídeo para YouTube. Así se garantiza la interacción en redes sociales; en este espacio el valor no tiene relación económica sino consumista pues prevalece la cantidad de veces en que se comparte un material que se produce.

\section{Consumir y producir información}

La esencia de esta era tiene relación directamente proporcional con lo rápido. El tipo de contenido que se produce deberá ser capaz de consumirse a la menor velocidad posible. Dicha información, también, tendrá que aplicarse en forma colaborativa, personalizada e individualizada para la comunidad. Así se desarrolla una relación social que genera participación.

Los distintos interesados de la búsqueda digital deben estar conscientes de que la generación de contenidos es de carácter comunitario, solo así tendrá acogida en redes sociales (Alejandro \& García, 2015). Los usuarios tradicionales pueden considerarse pasivos porque no han tenido la voluntad de producir y consumir a la vez; entendiendo que todas las oportunidades que se ofrecen son consecuencias de la conectividad y el dinamismo que se explota en la creación de productos relevantes que proliferan en la red y se convierten en inversión en medios sociales.

Cuando se genera este tipo de contenidos, hay que considerar lo principal: elaborar temas con más opciones de visualización. Vídeos, informes y entrevistas que puedan convertirse en productos multimedia, capaz de resumir lo escrito; de esta manera, al proyectar un tema se requiere de fuentes dispuestas en un formato fácil de visualizar; además de creatividad y autonomía. Plantea la importancia de crear ambientes comunicativos móviles para generar conocimiento o entretenimiento; indiscutiblemente, información basada en una colaboración individual; pues cada ser humano decidirá qué investigar, qué editar como propuesta informativa y para eso se valió de su propia capacidad, de sus propios medios. 
"Jamás en la historia las personas han tenido la posibilidad de buscar de manera independiente tanta información acerca de tantos temas o acerca de tanta gente" (Friedman, 2005, pág. 25). Precisamente, esto marca la diferencia entre el presente y el pasado; en el primer caso hay autonomía; y, en el segundo, imperaba la voluntad política del medio para hacer pública una información.

Esta es la esencia del prosumidor: atribuir poder a través de la emancipación de medios. Él es libre de hacer lo que considere con la información que propone; por ejemplo, en la red social Twitter muchos ciudadanos comparten noticias que ocurren en su entorno y usando pocos caracteres. Es información de fácil acceso, de interés general pero que merma la calidad y capacidad de los medios tradicionales para tratar la noticia. De esta manera, las librería estáticas quedan relegadas por la versión virtual, por los libros de pantalla (Ortega \& Humanes, 2001) y lo intangible ahora posee nuevos formatos y formas informativas con la consecuente necesidad de crear contenidos para las diferentes plataformas digitales, algo ya no tan complicado.

\section{Los prosumidores y el periodismo en la era 2.0}

Los prosumidores de hoy son jóvenes, principales participantes en el contenido web, que combinan tecnología y audiencia. La denominada Generación Y son originarios de la década del 80 y viven una tercera revolución con tres principales movimientos: agrícola, industrial y ésta: la tecnológica (Berrocal, Campos-Domínguez, \& Redondo, 2014). Los medios tradicionales han cambiado, eso significa deshacerse de la unidireccionalidad de la información en la que el emisor y el receptor eran los únicos protagonistas.

Su participación era irrelevante porque aceptaban todo lo que consumía y el receptor captaba lo que pasaba alrededor sin discernir lo verídico de lo real. Con las tecnologías digitales, el perfil del comunicador evolucionó y se está "reconfigurando el paisaje de la profesión" (Salaverría, 2016); a pesar de que algunas corrientes la consideran adversas; otras, las visualizan como un impulso o regeneración. Éstas multiplican las oportunidades laborales por la democratización de fuentes y la libertad informativa así la noticia ha dejado de ser considerada como tal por el manejo que se le da a cada suceso (la rapidez es lo que impera) y de ello se desgarra un sin número de equívocos provocando que la información se tergiverse y pierda su esencia. El denominador común es la inmediatez, hay más valor en el tiempo en que se publica que en el contenido de la misma; lo más insignificante ahora tiene prioridad.

Se otorga trascendencia a cuanto tema se propone y los prosumidores abarcan un contenido diferente, ellos fabrican sus propios noticieros o dan un giro de $360^{\circ}$ a situaciones que no imaginables y ahora son una realidad aceptada. Un claro ejemplo es Youtube con más de cien mil millones de videos subidos se convierte en el motor de búsqueda número dos en el mundo. La mayoría de los productos representan el papel del prosumidor: hacer participar a los ciudadanos y crear la cultura de una audiencia en crecimiento.

El espacio online se ha transformado en algo importante, independiente y en pleno auge competitivo para promover el desarrollo de marcas. Hoy, existen propuestas independientes para promover valores o servicios a través de la popularización de contenidos y la difusión de los mismos, especialmente entre jóvenes y niños. La cooperación y propagación son la base de esta 
plataforma obviando la calidad (Universidad de Guadalajara, 2012). En Youtube se propone material con fines utilitarios; esto implica dos partes: el prosumidor como consumidor y la fusión-cooperación entre ellos; así aparecen los denominados "Youtubers", término que se ha popularizado ante las influencia de determinadas personas para viralizar contenidos. Estas piezas son mediadoras en la práctica del usuario y la instauración de colectividades que moldean valores, formas de vida e inciden en el grado de aceptación o rechazo de una marca. Para las corporaciones, las comunidades virtuales son muy útiles para promover la fidelidad del cliente.

Existe una frase clave en todo este ecosistema mediático: cambio de hábitos. En la era actual, internet es una herramienta económica poderosa (Aguado, 2013); pues sin ser un hábito financiero propiamente dicho, permite abaratar costos publicitarios y difundir la información sin limitaciones, solo se requiere la necesidad de crear y consistencia en difusión.

Los prosumidores no son periodistas de profesión. Son generadores de contenido que se valen de la tecnología para llegar a las comunidades. Su papel es exponer contenidos con una mirada analítica y con afán de multiplicar ilimitadamente dicha difusión. Todos pueden convertirse en prosumidores con cuantiosas oportunidades de usar herramientas tecnológicas y ejecutar propuestas analíticas, eficaces y formativas. Se requiere habilidades para captar el interés público y, sobre todo, para ser críticos con las fuentes que proporcionan contenido. En la nueva sociedad de redes cada ciudadano se ha convertido en un internauta activo; los usuarios ya no son solo lectores, oyentes o telespectadores inertes que reciben información de los medios, sino más bien individuos participativos. Según Triviño, "un usuario participativo es aquel que tienen la posibilidad de compartir imágenes, videos, textos..." todo esto le confiere un enorme poder dentro de una cultura digital desarrollada.

\section{Conclusiones}

El consumidor de información ya no es un ser pasivo que recibe la información empaquetada por otros, él también quiere producir información (Ramonet, La explosión del periodismo, 2012). Dicho contenido se convierte en un arma de doble filo, ya que los usuarios se enfrentan a una convergencia mediática. "Un nuevo escenario donde generar contenidos se encuentra en un entorno en el que desaparecen las fronteras entre medios masivos" (Acosta, 2010, pág. 15). Es a este nuevo fenómeno con múltiples dimensiones donde los medios actuales deberán adaptarse y sobre todo generar contenidos interactivos. Ya no se trata de noticias, sino de contenidos multimedia. El periodismo digital puede jugar a descomponer un tema en múltiples enfoques, los cuales pueden desarrollarse con diferentes herramientas (Echevarría, 2010 ). Dichas herramientas ayudan a mostrar nuevos espacios de la realidad, que antes estaban ocultos, aportando así volumen y dimensión a la historia.

Los medios de comunicación de masas continúan con sus soportes tradicionales, se adecuan a estas nuevas plataformas y otros surgen exclusivamente para estar presentes sólo en la red. En Ecuador una propuesta informativa relevante es el diario digital La República liderado por Carlos Jijón y cuya disciplina periodística se ha mantenido por más de seis años en las plataformas digitales, brindando noticias actualizadas de manera constante y con diversos enfoques. Con casi tres millones de lectores en su cuenta Twitter, The New York Times, cuenta con tres veces más usuarios en esa red que ejemplares de su edición impresa, este se convierte en 
un ejemplo que evidencia el alcance del buen manejo de las tecnologías en relación con los medios tradicionales. "Internet no es un medio de comunicación "matiza Jeff Jarvis, profesor de periodismo en la City University; sin embargo los medios de comunicación lo ven como eso.

Los constantes cambios digitales requieren que los nuevos periodistas se adapten a esta convergencia de redes. Además de multimedia, el periodismo digital es multiplaforma (Rubio \& Zambrano, 2015); es decir los comunicadores deben desarrollar habilidades y competencias, lo cual lleva a la convergencia de redacciones y capacidad de editar contenidos para celulares, tabletas e incluso pantallas gigantes. Es así que en esta nueva era, existen transformaciones y nuevos espacios que día a día abren oportunidades para los futuros profesionales. En las salas de redacción cada vez más necesitan personal dinámico y especializado en el manejo de información en la web. En los diarios papel el ciclo productivo sigue siendo de 24 horas, en los sitios periodísticos online ya no hay ciclo, o es 24/7/365, esto es 24 horas al días de la semana, todos los días del año (Triviño, 2015 ).

Las redes sociales y la web 2.0 permiten a los periodistas completar cada noticia, añadiendo un matiz, un comentario, una cita una foto o un video, es por ello que hablar de un periodista activo digital, representa inmiscuirse en mundo donde la tecnología no solo equipará las tendencias de información sino también el manejo de las nuevas plataformas. Es de vital importancias que el periodista profesional, se tome su tiempo necesario para contrastarla información, corregirla y confirmarla (Ramonet, 2012).

Un nuevo escenario para la gestión de información está emergiendo y los futuros profesionales tienen ante sí un gran desafío, donde las nuevas formas de generar información constituyen un avance importante en esta era del periodismo. Así las nuevas leyes de la comunicación y la información en internet aún están por definir, pero lo que es seguro con la Web 2.0, es que ya no serán los periodistas sino los internautas quienes las van a determinar (Garcia, 2015).

\section{Bibliografía}

Acosta, A. P. (2010). La convergencia mediática: un nuevo escenario para la gestión de información. Obtenido de Scielo.sld: http://scielo.sld.cu/scielo.php?script=sci_arttext\&pid=S102494352003000500003

Aguado, J. M. (2013). la comunicacion móvil: hacia un nuevo ecosistema digital . Barcelona.

Alejandro, R., \& García, A. (2015). Instituto de Investigaciones Bibliotecológicas y de la Información de la UNAM. Obtenido de Instituto de Investigaciones Bibliotecológicas y de la Información de la http://www.scielo.org.mx/scielo.php?script=sci_arttext\&pid=S0187358X2016000200121

Berrocal, S., Campos-Domínguez, E., \& Redondo, M. (2014). Prosumidores mediáticos en la comunicación política: El «politainment» en YouTube. Comunicar, Vol. XXI, núm. 43, pp. 65-72pp. 65-72. Obtenido de Redalyc: http://www.redalyc.org/articulo.oa?id=15831058008 
Echevarría, M. C. (2010 ). Periodismo en la Web. : Editorial Las Brujas .

Friedman, T. (2005). La tierra es plana. Breve historia del mundo globalizado del siglo XXI. España: Martínez Roca.

Garcia, D. (2015). Prácticas periodísticas profesionales en los medios digitales de la ciudad de Cordova . Obtenido de Prácticas periodísticas profesionales en los medios digitales de la ciudad de Cordova http://www.alaic2015.eci.unc.edu.ar/files/ALAIC/EJE6/alaic\%206_68.pdf

García-Galera, M. C., \& Valdivia, A. (julio-diciembre de 2014). Prosumidores mediáticos. Cultura participativa de las audiencias y responsabilidad de los medios. Comunicar, vol. XXI, núm. 43, pp. 10-13. Obtenido de Redalyc: http://www.redalyc.org/articulo.oa?id=15831058002

Guadalajara, U. d. (2012). Comunicación y Sociedad. Mexico D.F. Islas, O. (21 de Septiembre de 2015). La ecología de los medios: metadisciplina compleja y sistémica. Obtenido de Scielo:

Islas, O., \& Carmona, J. (junio de 2008). Redalyc. Obtenido de El prosumidor. El actor comunicativo de la sociedad de la ubicuidad:

Kovach, B., \& Rosenstiel, T. (2012). Los elementos del periodismo. Aguilar.

Ortega, F., \& Humanes, M. (2001). Algo más que periodistas. Sociología de una profesión. Revista Española de Investigaciones Sociológicas, Núm. 93, pp. 296300.

Ramonet, I. (2012). La explosión del periodismo. Madrid: Clave intelectual. , $2^{\text {o }}$ edición.

Rodriguez, A. (2015). Las nuevas pautas para el acceso a la información. Obtenido de Scielo: http://www.scielo.org.mx/scielo.php?script=sci_arttext\&pid=S0187358X2016000200121

Rubio, A. B., \& Zambrano, W. (2015). Anagramas - Universidad De Medellin. Obtenido de Convergencia Digital: Nuevos perfiles de periodistas: http://www.scielo.org.co/pdf/angr/v13n26/v13n26a12.pdf

Salaverría, R. (Marzo-abril de 2016). Redefinir al Comunicador. El profesional de la información, Marzo - abril; vol. 25, núm. 2 eISSN: 1699-2407 . Obtenido de El profesional de la información: http://www.elprofesionaldelainformacion.com/contenidos/2016/mar/02.pdf

Soto, O. (2010). Los prosumidores y el periodismo en Internet. Obtenido de Clases de periodismo: http://www.clasesdeperiodismo.com/2010/05/22/los-prosumidoresy-el-periodismo-en internet/

Triviño, A. I. (2015 ). Herramientas digitales para periodistas . UOC. 